\begin{tabular}{|c|c|}
\hline 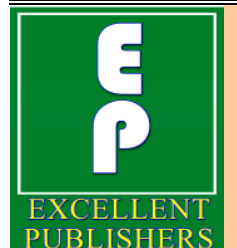 & $\begin{array}{c}\text { International Journal of Current Research in } \\
\text { Biosciences and Plant Biology } \\
\text { ISSN: 2349-8080 (Online) } \bullet \text { Volume } 3 \bullet \text { Number } 7 \text { (July-2016) } \\
\text { Journal homepage: www.ijcrbp.com }\end{array}$ \\
\hline
\end{tabular}

\title{
Studies on Effects of Inoculation of Glomus mosseae and Plant Growth Promoting Rhizomicroorganisms (PGPR) on Plectranthus amboinicus (Lour.) Spreng
}

\author{
Soniya Kasliwal*, Hossein Ramzan Nezhad and K. M. Srinivasamurthy \\ Department of Microbiology and Biotechnology, Jnanabharathi Campus, Bengaluru, Karnataka-56o o56, India \\ *Corresponding author.
}

\begin{abstract}
A b s t r a ct
Arbuscular Mycorrhizae (AM) is a type of endomycorrhizae in which fungus penetrates the cortical cells of roots of higher plants and forms vesicles and arbuscules. Plectranthus amboinicus (Lour.) Spreng is a perennial belonging to family Lamiaceae.In the current study open pot experiments were conducted to understand the influence of Arbuscular mycorrhizae Glomus mosseae and Phosphate solubilizers Trichoderma viride, Aspergillus awamori and Trichoderma harzianum for 60,120 and 180 Days. Physical growth parameters like shoot and root length, stem and root girth, fresh and dry weight, root volume and leaf area were studied. Percentage root colonization studies were done and biochemical parameters pertaining to chlorophyll and carotenoid analysis were done. Glomus mosseae with Trichoderma viride proved to be the best treatment for Plectranthus amboinicus plant with maximum increase in shoot length, fresh weight, dry weight, number of leaves and number of branches. Percentage root colonization results revealed a consistent increase in Glomus mosseae with Trichoderma viride for 60,120 and 180 days. Maximum increase in chlorophyll and carotenoid pigments was found in Glomus mosseae and Aspergillus awamori interaction. However future studies can be performed for standardizing different combinations of phosphate solubilizing fungi and arbuscular mycorrhizae species.
\end{abstract}

\author{
Article Info \\ Accepted: 01 July 2016 \\ Available Online: 06 July 2016
}

Keywords

Arbuscular mycorrhizae Phosphate solubilizer

Plant growth promoting microbes

Plectranthus amboinicus

\section{Introduction}

The term mycorrhizae was coined by A.B.Frank in 1885 (Frank, 1885). Mycorrhizae is the mutualistic symbiotic association between soil borne fungi and roots of higher plants in which both are benefitted (Sieverding, 1991; Sayeeda et al., 2013). Arbuscular mycorrhizae (AM) is a type of endomycorrhizae in which fungus penetrates the cortical cells of roots of higher plants and forms vesicles and arbuscules. Arbuscules are structures produced within the host plant cells by the AM fungi. These structures are responsible for the transfer of absorbed nutrients from the fungus to the plant
(Sandeepa, 2013). Arbuscular mycorrhizae are recognized as biofertilizers (Bohra et al., 2007). AM are known to increase in biomass of plant (Karthikeyan et al., 2008; Kumar et al., 2008), nutrient content (Das et al., 2007), bioremediation ( $\mathrm{Li}$ et al., 2006) and biological control of root pathogens (Reddy et al., 2006; Aditya et al., 2009).

Plectranthus amboinicus (Lour.) Spreng belonging to the Lamiaceae family, is a perennial with 3- to 10-years life span, and is distributed in Tropical Africa, Asia and Australia (Chang et al., 2010). This grassy plant is found or cultivated throughout India, Ceylon and Moluccas 
(Nadkarni, 2002; Rout et al., 2012). Plectranthus amboinicus, is used as food, additive and fodder, and especially as medicine in treating a wide range of diseases (Lukhoba et al., 2006). It is a folkloric medicinal plant used to treat malarial fever, hepatopathy, renal and vesicle calculi, cough, chronic asthma, hiccough, bronchitis, helminthiasis, colic, convulsions, and epilepsy (Chopra et al., 1956; Kirtikar and Basu, 1975; Nadkarni, 1996). For chemical composition of Plectanthus amboinicus as an aqueous extract, the major components are 3-carene, g-terpinene, camphor and carvacrol (Vera et al., 1993). The leaves have many traditional medicinal uses, especially for the treatment of coughs, sore throats and nasal congestion, and also other problems such as infections, rheumatism and flatulence. In Indonesia Cuban Oregano is a traditional food used in soup to stimulate lactation for the month or so following childbirth .The leaf extract of Plectranthus amboinicus was externally used in the skin allergy in India (Harsha et al., 2003). In Taiwan, Plectranthus amboinicus is used to treat inflammatory disease or swelling symptoms (Chang et al., 2005). And in Chinese folk medicine for the treatment of cough, fever, sore throats, mumps, and mosquito bite (Lukhoba et al., 2006; Senthilkumar and Venkatesalu, 2010). Plectranthus amboinicus is traditionally used treating rheumatoid arthritis (Chang et al., 2010). Previous studies have revealed that the ethanol extract of Plectranthus amboinicus possesses nephroprotective and antioxidant effects against acetaminophen-induced nephrotoxicity and strong diuretics effect in rats (Palani et al., 2010). Plectranthus amboinicus also showed the ability to treat collageninduced arthritis in rats (Chang et al., 2010; Chiu et al., 2012).

Plant growth promoting Rhizomicroorganisms (PGPR) are one of the most effective and studied soil microorganisms which can promote plant performance. PGPR have shown the ability to solubilize unavailable Phosphorus to a form available for plant growth (Anusuya and Jeyrajan, 1998). Studies have reported an increase in growth and phosphorus uptake by plants through inoculation of Phosphate solubilizers in pot experiments (Omar, 1998; Vassilev, 2006). Trichoderma species are known to induce plant growth by producing growth regulating factors (Baker et al., 1986) and also by suppressing the activity of Pathogenic organisms (Michirina, 1995). Many studies have proved the potential of Trichoderma spp. as biological agents antagonistic to several plant pathogens (Sivan and Chet, 1993; Inbar et al., 1996; Kullnig et al., 2000; Naseby et al., 2000; Woo et al., 2006; Tondje et al., 2007).
Aspergillus awamori have shown increased growth and phosphorus uptake in mung bean (Jain et al., 2010). Studies have reported the synergistic effects of Trichoderma species with other Arbuscular Mycorrhizae and enhanced growth in plants have been reported (Tanwar et al., 2011).

The present study was undertaken to understand the response of. Plectranthus amboinicus to the AM fungus Glomus mosseae and Plant growth promoting Rhizomicroorganisms (PGPR) Trichoderma viride, Aspergillus awamori (AA) and Trichoderma harzianum (TH) for 60, 120 and 180 days inoculation under open pot conditions.

\section{Materials and methods}

\section{Soil preparation}

Soil and sand samples were collected from nurseries nearby Bangalore University and were autoclaved at $121^{\circ} \mathrm{C}$ at $15 \mathrm{lbs}$ pressure for two consecutive days. The experimental soil was red clay soil having $\mathrm{pH}$ value 8.1. The soil and sand were then mixed with autoclaved farm yard manure (FYM) in the ratio of 1:1:1(v: v).

\section{Glomus mosseae spores isolation and inoculation}

Mycorrhizal inoculums of Glomus mosseae (GM) were isolated using Wet sieving and Decanting Technique (Gerdemann and Nicolson, 1963). The Glomus mosseae spores identification was done following the keys provided by Trappe (Trappe, 1982) and Schenck and Perez (Schenck and Perez, 1990). GM spores were isolated as per the spore morphology and characteristics. GM inoculums were prepared as per funnel technique (Menge and Timmer, 1982). GM cultures of $2 \mathrm{~g}$ (spore density -125 spores/g) were added near the roots of plant seedlings.

\section{Maintenance of Trichoderma viride, Aspergillus awamori (AA) and Trichoderma harzianum (TH)}

Initial cultures of Trichoderma viride (TV), Aspergillus awamori (AA) and Trichoderma harzianum (TH) were procured from Department of Soil Microbiology, University of Agriculture Sciences, Gandhi Krishi Vignana Kendra, Bangalore. TV, AA and TH cultures were then grown on $2 \%$ PDA and incubated for 7 days at $26 \pm 2^{\circ} \mathrm{C}$. Conidia from each isolate were then harvested by flooding the cultures with sterile distilled water. The culture surface was then rubbed with a sterile glass rod. 
The suspensions were filtered through out two layers of cheese cloth. The concentration of propagules in suspension were standardized with the aid of a haemocytometer to $3 \times 10^{8}$ conidia per $\mathrm{ml}$ for each.

\section{Experimental design}

One month old plant saplings of Plectranthus amboinicus were collected from Dhanvanthri Vana, Department of Indian System of Medicine and Homeopathy, Karnataka Forest Department, Jnana Bharathi campus, Bangalore University. The experiments were conducted as open pot experiments in plastic pots with $4 \mathrm{~kg}$ soil capacity. The plants were maintained at Medicinal Plant Garden, Department of Microbiology and Biotechnology, Bangalore University, Bangalore with the following inoculation treatments:

\section{Control : Uninoculated Plant \\ GM : Glomus mosseae \\ $\mathrm{GM}+\mathrm{TV}$ : Glomus mosseae + Trichoderma viride \\ $\mathrm{GM}+\mathrm{AA}$ : Glomus mosseae + Aspergillus awamori \\ GM + TH: Glomus mosseae + Trichoderma harzianum}

All the treatments were done in triplicates. The experiments were laid down as a Randomized complete block design (RCBD).The plants were maintained for 60 days and were watered on alternate days. During the experiments the temperature range was $14^{\circ} \mathrm{C}$ to $35^{\circ} \mathrm{C}$. Plants were harvested after 60, 120 and 180 days after transplanting (DAT) by using water pressure. Just after plucking the physical growth parameters viz., root length, shoot length, fresh weight, number of leaves etc were recorded. Plant samples were then oven dried at $60^{\circ} \mathrm{C}$ for $72 \mathrm{hrs}$ till a consecutive weight is achieved and later the dry weight was recorded.

\section{Physical parameters study}

After uprooting, various physical growth parameters of the plants such as shoot length (SL), root length(RL), stem girth (SG), root girth (RG), number of leaves (NOL), number of branches (NOB), fresh weight of shoot (FWSh), fresh weight root (FWR), dry weight of stem (DWS), dry weight root (DWR), dry weight leaves (DWL), root volume (RV), leaf area (LA) (Daughtry, 1990) and soil pH (Jackson, 1973) were measured.

\section{Root colonization study}

After 60 days of inoculation plants were harvested and terminal roots were collected from the plants. The roots were taken out carefully to prevent any damage to secondary or tertiary rootlets. After harvesting roots were rinsed thoroughly with tap water to remove soil particles and later with distilled water. Root Colonization was studied by 'Rapid clearing and staining technique' (Philips and Hayman, 1970). The technique involves microscopic observation of AM fungal colonization after clearing roots in $\mathrm{KOH}(10 \%)$ and staining with trypan blue $(0.5 \%)$. Percentage mycorrhizal root colonization (\%) study was done by gridline intersect method (Giovannetti and Mosse, 1980). A total of 50 root fragments were studied and infected root segments were recorded. A root segment was considered to be infected if it showed presence of mycelium, vesicle or arbuscules.

\section{Chlorophyll and carotenoid pigment analysis}

The chlorophyll pigments in the leaves were estimated following the method of Arnon (Arnon, 1949). The fully expanded leaves from all the sites were collected in the poly-thene bags and transported to the laboratory. The leaves were thoroughly washed with distilled water. Three replicates were used for each plant. Weighted fresh leaf material was homogenized and extracted thrice in chilled $80 \%$ acetone $(\mathrm{v} / \mathrm{v})$. The volume of the acetone extract was made up to a known one and the optical density was read at $645 \mathrm{~nm}$ and $663 \mathrm{~nm}$ wavelengths on a spectrophotometer. The concentration of the chlorophyll pigments was calculated using Arnon equation and the results are expressed in $\mathrm{mg} / \mathrm{g}$ fresh weight. Quantitative determination of carotenoids was done by reading the chlorophyll extract at $480 \mathrm{~nm}$. The amount of carotenoids present in the extract was calculated by using the formula of Krik and Allen (1965).

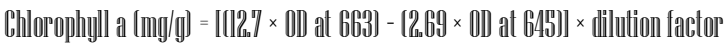

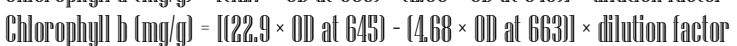

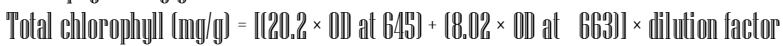

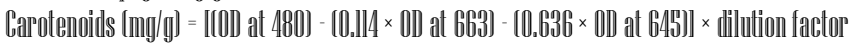

\section{Results and discussion}

Fresh weight of leaves, shoot, stem and roots were studied and also total fresh weight was calculated. The dry weight of stem, root and leaves were also calculated. In 60 Days treatment (Fig. 1) the shoot length (SL) was found to be maximum in GM+TH $(24.00 \mathrm{~cm})$ which is $9 \%$ more than control plant. GM, GM +TV and GM +AA also had higher shoot length than control plant. The root length (RL) was recorded to be highest in control plant for 60 Days inoculation (Table 1). The reason might be control plant is trying hard for nutrient supply and so morphological root shape difference. 


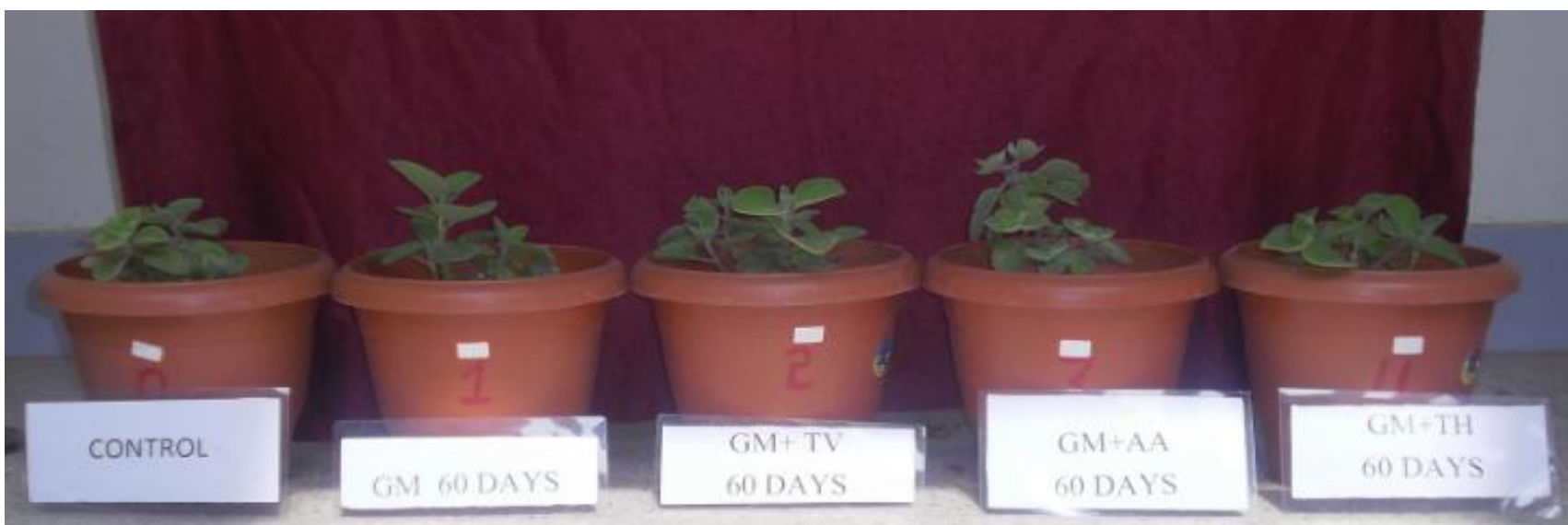

Fig. 1: Plectranthus amboinicus plant after 60 days treatment.

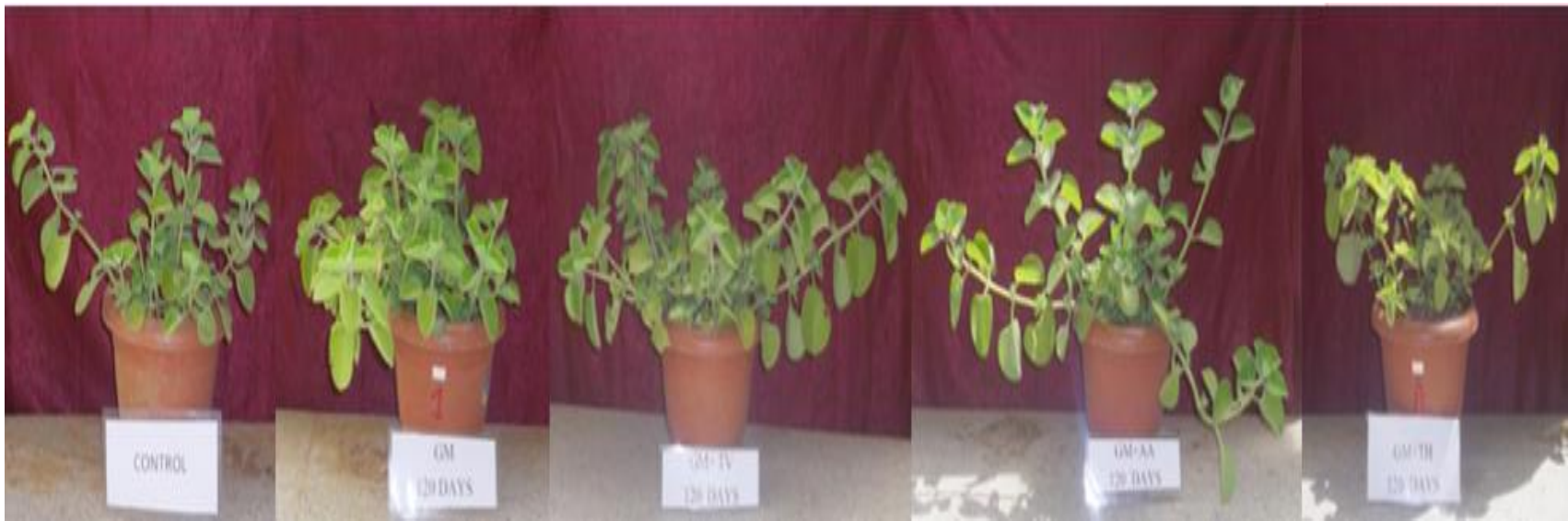

Fig. 2: Plectranthus amboinicus plant after 120 days treatment.

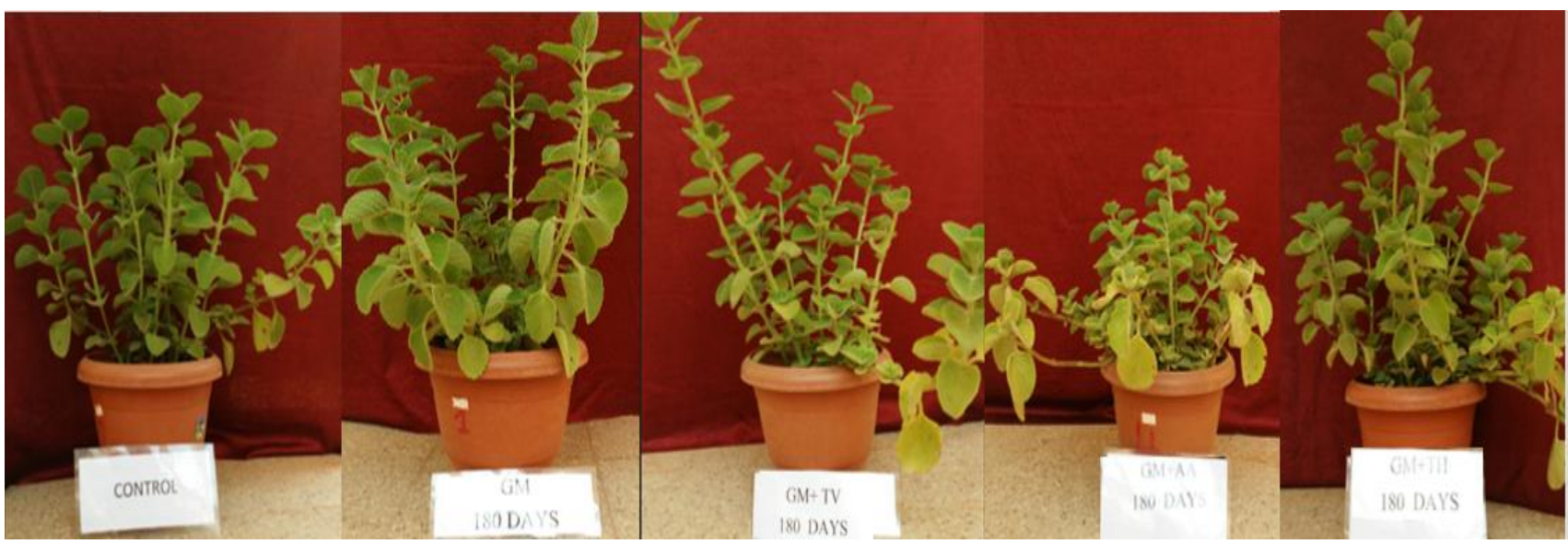

Fig. 3: Plectranthus amboinicus plant after 180 days treatment.

The stem girth (SG ) and root girth (RG) were measured using Vernier caliper.Stem of control plant was found to be most thick with $0.65 \pm 0.03 \mathrm{~cm}$ which was slightly more than $\mathrm{GM}+\mathrm{TH}(0.64 \pm 0.04 \mathrm{~cm}) . \mathrm{GM}$ has $0.41 \pm 0.2$ $\mathrm{cm}, \mathrm{GM}+\mathrm{TV}$ had $0.46 \pm 0.04 \mathrm{~cm}$ and $\mathrm{GM}+\mathrm{AA} \quad 0.47 \pm$ $0.08 \mathrm{~cm}$. The $R G$ showed a variable pattern from stem girth. The roots of GM +AA treatment were found to be most thick $(0.88 \pm 0.08 \mathrm{~cm})$ followed by GM+TV $(0.55$ $\pm 0.22 \mathrm{~cm})$. Control plants and GM+TH had nearby same RG with $(0.21 \pm 0.09 \mathrm{~cm})$ and $(0.21 \pm 0.02 \mathrm{~cm})$. RG in $\mathrm{GM}$ inoculated was found to be less with $0.17 \pm 0.05 \mathrm{~cm}$. Number of leaves (NOL) and number of branches (NOB) were observed to be highest in GM + AA treatment with number of leaves being $129.00 \pm 58$ and branches being $11.00 \pm 2.00$ (Table 1). Numbers of leaves were $30 \%$ more than control $(99.00 \pm 34.00)$ and 
$25.24 \%$ more than GM $(103 \pm 32.00)$ and were $103 \pm$ 44.00 for $\mathrm{GM}+\mathrm{TH}$ treatment $103 \pm 44.00$. The NOB were found to be highest in GM +AA treatment $(11.00$ \pm 2.00 ) for 60 Days treatment which was followed by $\mathrm{GM}+\mathrm{TH} \quad(10.00 \pm 4.00)$ and $\mathrm{GM}(8.00 \pm 2.00)$. GM +TV and control had almost same number with GM +TV $(7.00 \pm 1.00)$ and control $(7.00 \pm 2.00)$. The leaf area (LA) was found to be $46.51 \pm 10.52 \mathrm{~cm}^{2}$ in GM +TV treatment which was followed by GM+AA treatment $(40.79 \pm$ $12.60 \mathrm{~cm}^{2}$ ). It was lowest in $\mathrm{GM}+\mathrm{TH}$ treatment with $23.50 \pm 1.45 \mathrm{~cm}^{2}$. Root girth (RG) and root volume (RV ) were analyzed for root morphology. The root volume was found to be maximum in GM + AA (19.69 \pm 16.81 $\left.\mathrm{cm}^{3}\right)$. It was nearly same for control $\left(19.77 \pm 0.77 \mathrm{~cm}^{3}\right)$ and GM $\left(19.87 \pm 14.77 \mathrm{~cm}^{3}\right)$. The RV was lowest in GM $+\mathrm{TV}\left(13.13 \pm 4.64 \mathrm{~cm}^{3}\right)$.

Table 1. Physical growth parameters in Plectranthus amboinicus plant.

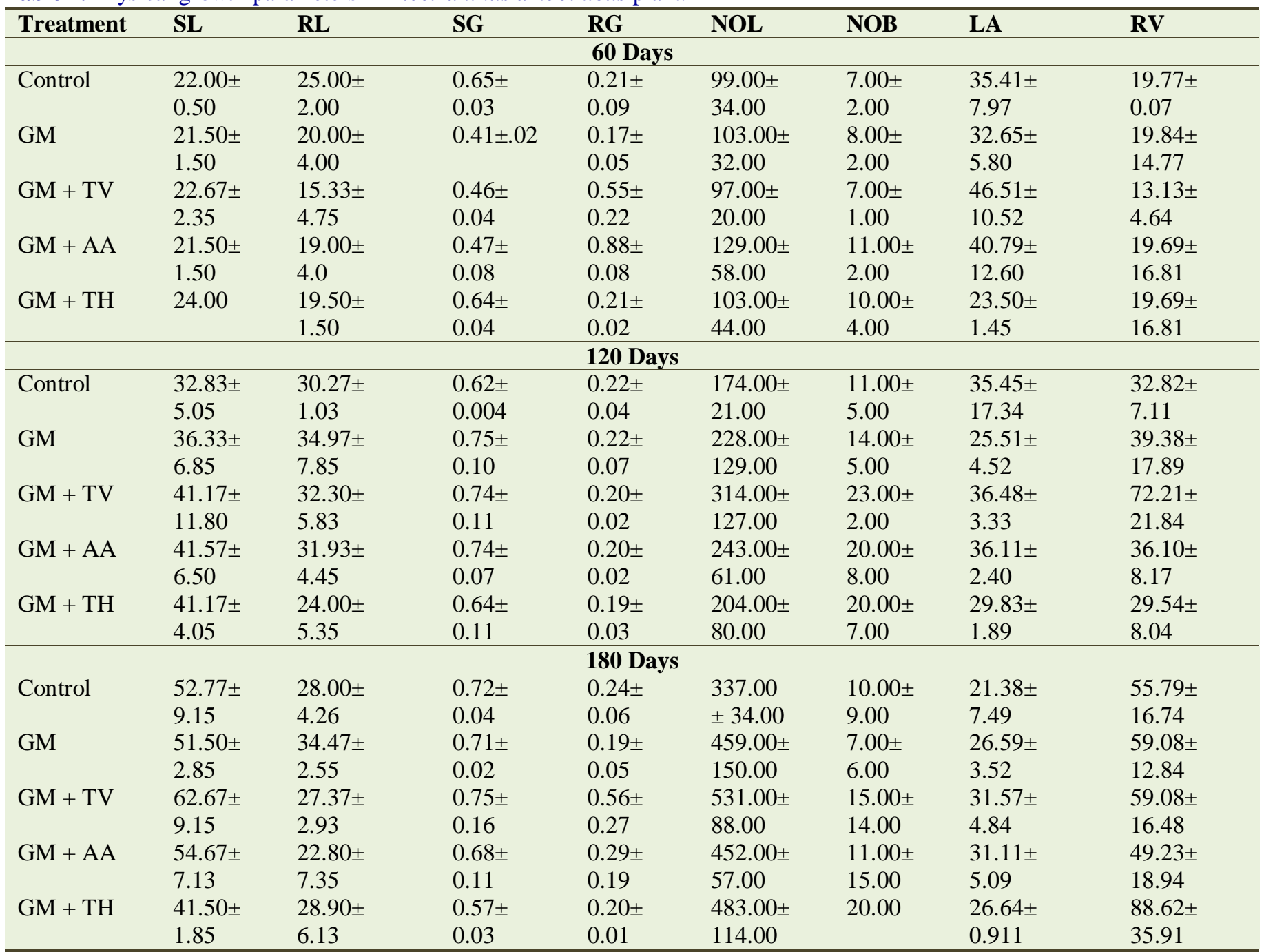

Note: * SL: Shoot length (cm); RL: Root length (cm); SG: Stem girth (cm); RG: Root girth (cm);

NOL: Number of leaves; NOB: Number of branches; LA: Leaf area $\left(\mathrm{cm}^{2}\right)$; RV: Root volume $\left(\mathrm{cm}^{3}\right)$;

*Values are mean of triplicates.

In 60 Days treatment the fresh weight of plant (FWP) was found to be maximum in GM $(70.52 \pm 9.89 \mathrm{~g})$ and then with control $(61.86 \pm 6.20 \mathrm{~g})$ (Table 2). The GM +AA inoculation had $61.73 \pm 0.28 \mathrm{~g}$ and $\mathrm{GM}+\mathrm{TH}$ had 61.10 $\pm 1.69 \mathrm{~g}$. Lowest FWP was found to be in GM $+\mathrm{TV}(57.28$ $\pm 9.56 \mathrm{~g}$ ). The dry weight of plant (DWP) was found to be maximum in GM +AA (3.56 $\pm 0.36 \mathrm{~g})$ and control had
(3.45 $\pm 0.28 \mathrm{~g})$. The GM inoculation had dry weight $(3.06$ $\pm 0.80 \mathrm{~g})$ and $\mathrm{GM}+\mathrm{TV}(3.09 \pm 0.41 \mathrm{~g})$. The fresh weight of shoot (FWSh) was found to be maximum $(63.73 \pm 11.69 \mathrm{~g})$ in GM inoculation. It was $56.75 \pm 5.98 \mathrm{~g}$ in control. The lowest was found to be $50.52 \pm 10.64 \mathrm{~g}$ in $\mathrm{GM}+\mathrm{TV}$. The $\mathrm{GM}+\mathrm{AA}$ and GM+TH inoculation had fresh weight of shoot to be $52.95 \pm 0.50 \mathrm{~g}$ and $53.02 \pm 5.23 \mathrm{~g}$. 
Fresh weight of stem (FWS) was found to be highest in GM inoculation with $13.96 \pm 0.46 \mathrm{~g}$ which was $14.3 \%$ more than control plant. GM +AA treatment had 13.02 $\pm 2.06 \mathrm{~g}$ fresh weight of stem whereas it was $11.48 \pm$ $1.77 \mathrm{~g}$ for $\mathrm{GM}+\mathrm{TH}$.The minimum stem weight was observed for GM $+\mathrm{TV}$ interaction $(8.98 \pm 3.64 \mathrm{~g})$. The dry weight of stem was found to be maximum $1.15 \pm$ $0.11 \mathrm{~g}$ in $\mathrm{GM}+\mathrm{AA}$ showing that $\mathrm{GM}+\mathrm{AA}$ interaction is increasing dry mass of Plectranthus amboinicus plant which was $35 \%$ more than control plant .It was $121 \%$ more than GM plant ( $0.52 \pm 0.44 \mathrm{~g})$ and $45.5 \%$ than $\mathrm{GM}+\mathrm{TV}(0.79 \pm 1.17 \mathrm{~g})$.

Fresh weight of root (FWR) and dry weight of roots (DWR) were observed. The FWR and DWR were found to be maximum in GM +AA which is $8.73 \pm 0.79 \mathrm{~g}$ (FWR) and $0.79 \pm 0.13$ (DWR). The FWR for control plant was found to be minimum $0.58 \pm 0.07 \mathrm{~g}$ which was $36 \%$ less than GM +AA. GM +AA had FWR 66\% more than control, $26.8 \%$ more than GM $(6.88 \pm 2.03 \mathrm{~g})$, $33.28 \%$ more than control plant and $46.29 \%$ more than GM. The GM +TV treatment had $0.56 \pm 0.09 \mathrm{~g}$ of DWR.

The fresh weight of leaves (FWL) was found to be highest in GM treatment for 60 Days which is found to be $53.51 \pm 12.35 \mathrm{~g}$ followed by control $(48.36 \pm 3.15 \mathrm{~g})$ and for $\mathrm{GM}+\mathrm{TV}$ it is $44.01 \pm 6.28 \mathrm{~g}$ and $44.01 \pm 2.43 \mathrm{~g}$ for $\mathrm{GM}+\mathrm{AA}$ treatment .The dry weight of leaves (DWL) was found to be highest in GM $(2.00 \pm 0.48 \mathrm{~g})$ and lowest in $\mathrm{GM}+\mathrm{AA}(1.63 \pm 0.13 \mathrm{~g})$.

While studying for 120 Days treatment the SL was found to be maximum in $\mathrm{GM}, \mathrm{GM}+\mathrm{AA}(41.57 \pm 6.50 \mathrm{~cm})$ followed by GM $+\mathrm{TV}(41.17 \pm 11.80 \mathrm{~cm})$. The $\mathrm{GM}+\mathrm{TH}$ treatment was found to be $41.17 \pm 4.05 \mathrm{~cm}$. It was lowest for control $(32.83 \pm 5.05 \mathrm{~cm})$. All the treatments had higher shoot length than control plants.

The RL was found to be maximum in GM $(34.97 \pm 7.85$ $\mathrm{cm})$ followed by GM +TV $(32.30 \pm 5.83 \mathrm{~cm}), \mathrm{GM}+\mathrm{AA}$ $(31.93 \pm 4.45 \mathrm{~cm})$, control $(30.27 \pm 1.03 \mathrm{~cm})$. The minimum root length was found to be in GM+TH (24.00 $\pm 5.35 \mathrm{~cm}$ ). Although all treatments had higher RL than control $(63.10 \pm 5.23 \mathrm{~cm})$ with GM $(71.30 \pm 13.88 \mathrm{~cm})$ and $\mathrm{GM}+\mathrm{TH}(65.17 \pm 5.57 \mathrm{~cm})$.

The SG and RG were also analyzed. The SG was maximum in GM $(0.75 \pm 0.10 \mathrm{~cm})$ with almost nearby values to $\mathrm{GM}+\mathrm{TV}(0.74 \pm 0.11 \mathrm{~cm})$ and $\mathrm{GM}+\mathrm{AA}(0.74$ $\pm 0.07 \mathrm{~cm})$. GM+TH had value of $0.64 \pm 0.11 \mathrm{~cm}$, whereas control had $0.62 \pm 0.004 \mathrm{~cm}$. The RG was found to be maximum in GM $(0.22 \pm 0.07 \mathrm{~cm})$ and control also had value of $0.02 \pm 0.04 \mathrm{~cm}$. It was found to be $0.20 \pm$ $0.02 \mathrm{~cm}$ in $\mathrm{GM}+\mathrm{TV}$ and $0.20 \pm 0.02 \mathrm{~cm}$ in $\mathrm{GM}+\mathrm{AA}$ inoculations. The lowest stem girth was noted in $\mathrm{GM}+\mathrm{TH}$ inoculation for 120 Days interval.

Tremendous change was noticed in NOL from 60 days to 120 days. The number of leaves increased many fold with 60 days to 120 days (Fig. 2). The NOL increased many folds with 60 days interval. The maximum number of leaves were observed in GM +TV $(314 \pm 127)$ which is $80.45 \%$ more than control. The NOL after control were followed by GM+TH $(204 \pm 80)$, GM $(228 \pm 129)$ and $\mathrm{GM}+\mathrm{AA}(243 \pm 61)$.

When compared for NOB and LA, they were also found to be maximum in $\mathrm{GM}+\mathrm{TV}$ treatment with $23.00 \pm 2.00$ NOB and $36.48 \pm 3.33 \mathrm{~cm}^{2} \mathrm{LA}$. The NOB was found to be minimum in control plants. NOB were $109 \%$ more than control plants $(11.00 \pm 5.00), 64 \%$ more than GM $(14.00 \pm 5.00)$, and almost $15 \%$ higher than GM + AA $(20.00 \pm 8.00)$ and $\mathrm{GM}+\mathrm{TH}(20.00 \pm 7.00)$. The LA when studied was maximum in GM +AA treatment. It was almost nearby equal to GM +AA treatment which is $36.11 \pm 2.40 \mathrm{~cm}^{2}$ and control $\left(35.45 \pm 17.34 \mathrm{~cm}^{2}\right)$. The leaf area for GM $\left(25.51 \pm 4.52 \mathrm{~cm}^{2}\right)$ and $\mathrm{GM}+\mathrm{TH}$ were $29.83 \pm 1.89 \mathrm{~cm}^{2}$. When root volume (RV) was studied, the RV was also observed with tremendous increase in $\mathrm{GM}+\mathrm{TV}$ interaction. GM + TV had highest root volume of $72.21 \pm 21.84 \mathrm{~cm}^{3}$ which is almost $123 \%$ more than control $\left(32.82 \pm 7.11 \mathrm{~cm}^{3}\right)$. The RV was found to be least for GM+TH $\left(29.54 \pm 8.04 \mathrm{~cm}^{3}\right)$. For GM interaction it is $39.38 \pm 17.89 \mathrm{~cm}^{3}$ and for $\mathrm{GM}+\mathrm{AA}$ interaction it was found to be $36.10 \pm 8.17 \mathrm{~cm}^{3}$.

For 180 days of treatment (Fig . 3), the FWP was found to be maximum in GM +TV treatment $(744.61 \pm 182.02$ $\mathrm{g})$ which is $35.87 \%$ more than control $(548.10 \pm 134.05$ g). GM had FWP $623.58 \pm 156.50 \mathrm{~g}$ and $\mathrm{GM}+\mathrm{TH}$ had $663.47 \pm 202.07$ g. GM + AA treatment had value of $563.24 \pm 169.30 \mathrm{~g}$. The dry weight of plant (DWP) was observed to be maximum in GM+TH $(43.07 \pm 11.21 \mathrm{~g})$. DWP of GM +TV was $33.07 \pm 5.56 \mathrm{~g}$ and $\mathrm{GM}+\mathrm{AA}$ was $38.34 \pm 14.05 \mathrm{~g}$. The DWP for GM was $21.14 \pm 4.27 \mathrm{~g}$ and control had minimum value with $14.98 \pm 5.44 \mathrm{~g}$ (Table 2).

The fresh weight of shoot (FWSh) was $591.92 \pm 178.49$ $\mathrm{g}$ for the GM+TH, $676.29 \pm 191.35 \mathrm{~g}$ for GM +TV and $583.28 \pm 148.90 \mathrm{~g}$ for GM. Minimum was observed in control plant which is $509.46 \pm 137.69 \mathrm{~g}$. The FWS and DWS were maximum in GM +TV interactions $166.13 \pm$ $32.04 \mathrm{~g}$ and $132.85 \pm 45.92 \mathrm{~g}$ for $\mathrm{GM}+\mathrm{TH}$ interactions. 
Table 2. Fresh weight and dry weight analysis in Plectranthus amboinicus plant.

\begin{tabular}{|c|c|c|c|c|c|c|c|c|c|}
\hline Treatment & FWP & DWP & FWSh & FWS & DWS & FWR & DWR & FWL & DWL \\
\hline \multicolumn{10}{|c|}{60 Days } \\
\hline \multirow[t]{2}{*}{ Control } & $61.86 \pm$ & $3.45 \pm$ & $56.75 \pm$ & $12.21 \pm$ & $0.85 \pm$ & $5.24 \pm$ & $0.58 \pm$ & $48.36 \pm$ & $2.02 \pm$ \\
\hline & 6.20 & 0.28 & 5.98 & 1.31 & 0.02 & 0.07 & 0.04 & 3.15 & 0.26 \\
\hline \multirow[t]{2}{*}{ GM } & $70.52 \pm$ & $3.06 \pm$ & $63.73 \pm$ & $13.96 \pm$ & $0.52 \pm$ & $6.88 \pm$ & $0.54 \pm$ & $53.51 \pm$ & $2.00 \pm$ \\
\hline & 9.89 & 0.80 & 11.69 & 0.46 & 0.44 & 2.03 & 0.13 & 12.35 & 0.48 \\
\hline \multirow[t]{2}{*}{$\mathrm{GM}+\mathrm{TV}$} & $57.28 \pm$ & $3.09 \pm$ & $50.52 \pm$ & $8.98 \pm$ & $0.79 \pm$ & $6.55 \pm$ & $0.56 \pm$ & $44.01 \pm$ & $1.74 \pm$ \\
\hline & 9.56 & 0.41 & 10.64 & 3.64 & 0.17 & 0.84 & 0.09 & 6.28 & 0.26 \\
\hline \multirow[t]{2}{*}{$\mathrm{GM}+\mathrm{AA}$} & $61.73 \pm$ & $3.56 \pm$ & $52.95 \pm$ & $13.02 \pm$ & $1.15 \pm$ & $8.73 \pm$ & $0.79 \pm$ & $44.01 \pm$ & $1.63 \pm$ \\
\hline & 0.28 & 0.36 & 0.50 & 2.06 & 0.11 & 0.79 & 0.13 & 2.43 & 0.13 \\
\hline \multirow[t]{2}{*}{$\mathrm{GM}+\mathrm{TH}$} & $61.10 \pm$ & $3.22 \pm$ & $53.02 \pm$ & $11.48 \pm$ & $0.92 \pm$ & $7.81 \pm$ & $0.61 \pm$ & $45.40 \pm$ & $1.69 \pm$ \\
\hline & 1.69 & 0.17 & 5.23 & 1.77 & 0.09 & 3.57 & 0.30 & 3.33 & 0.05 \\
\hline \multicolumn{10}{|c|}{120 Days } \\
\hline \multirow[t]{2}{*}{ Control } & $243.07 \pm$ & $16.73 \pm$ & $221.31 \pm$ & $47.28 \pm$ & $5.11 \pm$ & $21.70 \pm$ & $3.11 \pm$ & $174.07 \pm$ & $8.51 \pm$ \\
\hline & 79.67 & 3.94 & 77.43 & 15.01 & 1.54 & 2.38 & 0.59 & 61.69 & 2.96 \\
\hline \multirow[t]{2}{*}{ GM } & $425.99 \pm$ & $26.09 \pm$ & $403.70 \pm$ & $68.59 \pm$ & $8.62 \pm$ & $25.50 \pm$ & $2.70 \pm$ & $363.14 \pm$ & $14.76 \pm$ \\
\hline & 187.87 & 11.17 & 175.70 & 29.94 & 4.02 & 9.81 & 0.97 & 186.81 & 6.28 \\
\hline \multirow[t]{2}{*}{$\mathrm{GM}+\mathrm{TV}$} & $435.17 \pm$ & $28.53 \pm$ & $400.23 \pm$ & $73.54 \pm$ & $8.87 \pm$ & $34.88 \pm$ & $4.43 \pm$ & $330.42 \pm$ & $15.23 \pm$ \\
\hline & 147.39 & 10.51 & 138.35 & 27.44 & 3.33 & 10.00 & 1.95 & 120.87 & 5.42 \\
\hline \multirow[t]{2}{*}{$\mathrm{GM}+\mathrm{AA}$} & $344.08 \pm$ & $21.29 \pm$ & $319.38 \pm$ & $93.98 \pm$ & $6.68 \pm$ & $24.04 \pm$ & $2.91 \pm$ & $251.62 \pm$ & $11.71 \pm$ \\
\hline & 161.87 & 8.56 & 158.17 & 82.72 & 3.05 & 4.26 & 0.88 & 115.197 & 5.06 \\
\hline \multirow[t]{2}{*}{$\mathrm{GM}+\mathrm{TH}$} & $279.83 \pm$ & $17.05 \pm$ & $252.05 \pm$ & $45.43 \pm$ & $6.41 \pm$ & $27.92 \pm$ & $2.203 \pm$ & $173.16 \pm$ & $8.44 \pm$ \\
\hline & 131.33 & 7.53 & 128.85 & 23.73 & 1.93 & 3.47 & 0.78 & 107.74 & 5.01 \\
\hline \multicolumn{10}{|c|}{180 Days } \\
\hline \multirow[t]{2}{*}{ Control } & $548.10 \pm$ & $17.98 \pm$ & $509.46 \pm$ & $118.35 \pm$ & $13.49 \pm$ & $38.86 \pm$ & $5.17 \pm$ & $390.90 \pm$ & $17.98 \pm$ \\
\hline & 134.05 & 5.44 & 137.69 & 11.15 & 2.26 & 7.61 & 0.85 & 126.68 & 5.44 \\
\hline \multirow[t]{2}{*}{ GM } & $623.58 \pm$ & $21.14 \pm$ & $583.28 \pm$ & $130.60 \pm$ & $16.56 \pm$ & $39.30 \pm$ & $6.06 \pm$ & $452.68 \pm$ & $21.14 \pm$ \\
\hline & 156.50 & 4.27 & 148.98 & 17.38 & 2.36 & 8.41 & 1.42 & 13.68 & 4.28 \\
\hline \multirow[t]{2}{*}{$\mathrm{GM}+\mathrm{TV}$} & $744.61 \pm$ & $33.07 \pm$ & $676.29 \pm$ & $166.13 \pm$ & $20.43 \pm$ & $58.32 \pm$ & $5.82 \pm$ & $510.15 \pm$ & $24.97 \pm$ \\
\hline & 182.02 & 5.56 & 191.35 & 32.04 & 1.94 & 12.29 & 0.14 & 159.57 & 6.004 \\
\hline \multirow[t]{2}{*}{$\mathrm{GM}+\mathrm{AA}$} & $563.24 \pm$ & $38.34 \pm$ & $511.26 \pm$ & $112.26 \pm$ & $14.03 \pm$ & $51.98 \pm$ & $4.78 \pm$ & $399.00 \pm$ & $19.33 \pm$ \\
\hline & 169.30 & 14.05 & 152.93 & 46.90 & 6.73 & 22.31 & 2.01 & 109.32 & 5.86 \\
\hline \multirow[t]{2}{*}{$\mathrm{GM}+\mathrm{TH}$} & $663.47 \pm$ & $48.07 \pm$ & $591.92 \pm$ & $132.85 \pm$ & $15.89 \pm$ & $71.64 \pm$ & $10.17 \pm$ & $459.07 \pm$ & $21.62 \pm$ \\
\hline & 202.07 & 11.21 & 178.49 & 45.92 & 2.76 & 23.82 & 3.60 & 132.65 & 5.58 \\
\hline
\end{tabular}

Note : *FWP : Fresh weight of plant (g); DWP : Dry weight of plant (g); FWSh : Fresh weight of shoot(g); FWS : Fresh weight of $\operatorname{stem}(\mathrm{g})$; DWS : Dry weight of stem $(\mathrm{g})$; FWR : Fresh weight of $\operatorname{root}(\mathrm{g})$; DWR : Dry weight of $\operatorname{root}(\mathrm{g})$; FWL : Fresh weight of leaves $(\mathrm{g})$; DWL : Dry weight of leaves $(\mathrm{g})$; * Values are mean of triplicates.

The FWS for GM interactions is $130.60 \pm 17.38 \mathrm{~g}$, $118.35 \pm 11.15 \mathrm{~g}$ in control and $112.26 \pm 46.90 \mathrm{~g}$ in $\mathrm{GM}$ +AA treatment. It was maximum DWS value for GM $+\mathrm{TV}$ which is $20.43 \pm 1.94 \mathrm{~g}$ and after that for GM which is $16.56 \pm 2.36 \mathrm{~g}$ for GM. The DWS for GM+TH was $15.89 \pm 2.76 \mathrm{~g}$ and $14.03 \pm 6.73 \mathrm{~g}$ for $\mathrm{GM}+\mathrm{AA}$ interactions.

The FWR was maximum in GM+TH interaction which is $71.64 \pm 23.82 \mathrm{~g}$ and so the dry weight of root (DWR) also $10.17 \pm 3.60 \mathrm{~g}$ maximum value. The dry weight was followed by GM with value being $6.06 \pm 1.42 \mathrm{~g}$, GM $+\mathrm{TV}$ had value of $5.82 \pm 0.4$ and control had value of $5.17 \pm 0.85 \mathrm{~g}$. The FWL was found to be maximum in $\mathrm{GM}+\mathrm{TV}$ interaction $(510.15 \pm 159.57 \mathrm{~g})$ followed by $\mathrm{GM}+\mathrm{TH}(459.07 \pm 132.65 \mathrm{~g})$. The DWL was also maximum in GM +TV $(24.97 \pm 6.004 \mathrm{~g})$. Control plants had DWL of $17.98 \pm 5.44 \mathrm{~g}$ whereas GM had $21.14 \pm$ $4.28 \mathrm{~g}, \mathrm{GM}+\mathrm{AA}$ had $19.33 \pm 5.86 \mathrm{~g}$ and $\mathrm{GM}+\mathrm{TH}$ had $21.62 \pm 5.58 \mathrm{~g}$.

When studying for SL and RL for 180 days interval, the SL was found to be maximum $62.67 \pm 9.19 \mathrm{~cm}$ in GM $+\mathrm{TV}$ but RL was maximum in GM+TH $(28.90 \pm 6.13$ g) interaction. The GM + TV interaction had highest values for NOL, SG and RG. The SG was observed to be $0.75 \pm 0.16 \mathrm{~cm}$, whereas RG was $0.56 \pm 0.27 \mathrm{~cm}$. NOL was also observed and found to be maximum in GM $+\mathrm{TV}$ which was $531 \pm 88$. All the treatments had higher number of leaves than control plants. The NOL of control plants was minimum with $337 \pm 34$. For GM interaction NOL was observed and found to be $459 \pm$ 
150 and for $\mathrm{GM}+\mathrm{AA}$ it was $452 \pm 57$. The NOL for $\mathrm{GM}+\mathrm{TH}$ were observed to be $483 \pm 114$. Increase in shoot length could be attributed to the AM colonization as it known to enhance plant growth by nutrient uptake and secreting plant growth hormones. The increase in height could be due to the greater rate of photosynthesis (Allen et al., 1981). The maximum increase in root length might be due to mycelial network of AM fungi which extends deeper to invade nutrient depletion zone. Kumar et al. (2008) while working on Spilanthes acmella, reported the maximum increase in root length when inoculated with AM fungi and Trichoderma viride (Aditya et al., 2009).

The leaf area LA was found to be maximum for GM $+\mathrm{TV}$ interaction which is $31.57 \pm 4.84 \mathrm{~cm}^{2}$. The root volume of plant was found to be maximum in $\mathrm{GM}+\mathrm{TH}$ treatment which is $88.62 \pm 35.91 \mathrm{~cm}^{3}$. Higher leaf area in AM inoculated plant might be as a result of enhanced nitrogen acquisition by host plant through the external hyphal transport of NO3 (Tobar et al., 1994a, b) or nitrogen assimilating enzymes (Cliquet and Stewart, 1993; Aditya et al., 2009).

The percentage root infection was found to be highest in GM at 60 DAT and 120 DAT and in GM +AA at 180 DAT (Table 3). Root colonization studies were done to calculate the percentage root infection in plant. Treatment GM+TV has shown consistent results and hence can be considered optimum and its root colonization was found to be $80 \%$ at 60 DAT and 120 DAT and $90 \%$ at 120 DAT. Slight change in $\mathrm{pH}$ was noticed for all the treatments which was slightly acidic for all the inoculated treatments and ranged from 6.5-6.8.

Table 3. Percentage root colonization in Plectranthus amboinicus.

\begin{tabular}{llll}
\hline \multirow{2}{*}{ Treatment } & \multicolumn{3}{l}{ Percentage of root colonization $(\%)$} \\
\cline { 2 - 4 } & 60 DAT & 120 DAT & 180 DAT \\
\hline Control & 0 & 0 & 0 \\
GM & 84 & 90 & 72 \\
GM+TV & 80 & 90 & 80 \\
GM +AA & 72 & 72 & 92 \\
GM +TH & 70 & 74 & 74 \\
\hline
\end{tabular}

The biochemical constituents (chlorophyll and carotenoid) were estimated by spectrophotometric analysis. GM +AA showed highest chlorophyll content at 60 DAT and 180 DAT while control showed highest amount at 120 DAT. Control showed highest carotenoid content at 60 DAT, while GM +AA had more carotenoids at $120 \mathrm{DAT}$ and GM+TV at $180 \mathrm{DAT}$.
Chlorophyll and carotenoids are photosynthetic pigments and their quantity in the plant will express its photosynthetic efficiency. The photosynthetic pigments chlorophylls and carotenoids, together with sterols, prenylquinones, and prenols, belong to the group of isoprenoid plant lipids. Both chlorophylls are genuine components of the photosynthetic membranes and occur in a ratio $(\mathrm{a} / \mathrm{b})$ of approximately 3 to 1 . The present findings may be due to the fact that growth conditions and environmental factors can modify $a / b$ ratio. The carotenoids of green, photosynthetically active plant tissue, which are needed for photosynthetic function, are classified as primary carotenoids. Percentage composition of carotenoids varies according to growth factors and stress factors (Lichtenthaler et al., 1981; Lichtenthaler, 1987).

Plectranthus amboinicus plant responded well with all the GM treatments. The enhanced growth is due to the ability of AM fungi to increase nutrient uptake of plants by developing an association with roots (Schreiner et al., 1997) and sometimes also by promoting the growth of other rhizospheric micro-organisms and thus enhancing plant growth (Johnson et al., 2004). The other reason can be that, once host roots are colonized by AM fungi, it changes the root exudates released and produces phosphatase enzyme in rhizosphere. These phosphatases produced by extraradical hyphae of AM fungi could hydrolyze extracellular phosphate ester bonds and ultimately made Phosphorus available to plants (Joner et al., 2000). Although the best response were given by Trichoderma species with Trichoderma viride and Trichoderma harzianum in 180 days interval. Considering the medicinal value of the plant for leaves Glomus mosseae with Trichoderma viride proved to be best inoculation treatment with Plectranthus amboinicus.

Earlier studies have also shown that Glomus mosseae increases plant height, stem girth, biomass, $\mathrm{P}$ content, $\mathrm{Zn}$ concentration, biovolume index and quality index than uninoculated control plants (Sumana and Bagyaraj, 1999; Sankaranarayana and Sundarababu, 2001). Studies performed by Rajeshkumar et al. (2008) have proved that Glomus mosseae have increased physical growth parameters in Plectranthus amboinicus plant. The efficacy of Trichoderma for plant growth promotion may be due to higher nutrient uptake particularly N, P, K, Fe, $\mathrm{Zn}$ and $\mathrm{Cu}$ in several crops including sugarcane (Howell, 2003; Shukla et al., 2008). Trichoderma are also known to produce a number of antibiotics such as trichodermin, trichodermal, polyketides, peptaboils, sesquterpenes and steroids. These antibiotics are associated with both 
biocontrol activity and of plant and root growth promotion (Harman et al., 2004; Chet et al., 2006; Aditya et al., 2009). The present result findings are in agreement with earlier work performed by Roldan et al. (1992), Monte and Llobell (2003), Medina et al. (2004) and Punamiya et al. (2010), on Glomus mosseae (Monte and Llobell, 2003; Gomathinayagam et al., 2012).

There have been tremendous advances in research on mycorrhizal physiology and ecology over the past few years which have led to a greater understanding of the multiple roles of AMF in the ecosystem . Therefore the present studies were performed to investigate the effects of Glomus mosseae and other Phosphate solubilizers viz., Trichoderma viride, Aspergillus awamori and Trichoderma harzianum on Plectranthus amboinicus. Based on the above studies performed it can be concluded that AM species, Glomus mosseae with phosphate solubilizer Trichoderma viride can be used as best consortia for Plectranthus amboinicus Lour. (Spreng). This technology being simple and eco-friendly can also be used by nurserymen for horticulture purposes or for its medicinal value. This study also provides a great future for utilizing the efficient strains of mycorrhizal fungi to exploit them for beneficial effects in establishment of seedlings and also reduce fertilizer application and also for economic production of Plectranthus amboinicus. Although further more studies can also be performed with trying different combinations of Phosphate solubilizers or different arbuscular mycorrhizae species.

\section{Conflict of interest statement}

Authors declare that they have no conflict of interest.

\section{Acknowledgement}

The authors want to acknowledge Department of Microbiology and Biotechnology, Bangalore University, Bangalore for providing research facilities.

\section{References}

Aditya, K., Ashok, A., Sunita, K., 2009. Influence of arbuscular mycorrhizal fungi and Trichoderma viride on growth performance of Salvia officinalis Linn. J. Appl. Natural Sci. 1(1), 13-17.

Allen, M.F., Smith, W. K., Moore, T.S., Chiristensen, M., 1981. Comparative water relation and photosynthesis of mycorrhizal and non-mycorrhizal Bouteluoa gracilis H.B.K. New Phytol. 88, 683-693.
Anusuya, D., Jeyrajan, R., 1998. Phosphorus solubilization by Trichoderma viride. Curr. Sci. 74, 264-265.

Arnon, D. I., 1949. Copper enzymes in isolated chloroplasts, polyphenoxidase in Beta vulgaris. Plant Physiol. 24, 1-15.

Baker, R., Paulitz, T., Windham, M. H., Elad, Y., 1986. Enhancement of growth of ornamentals by a biological control agent. Colorado Growers Assoc. Res. Bull. 431, 1.

Bohra, A., Mathur, N., Bohra, S., Singh, J., Vyas, A., 2007. Influence of AM fungi on physiological changes in Terminalia arjuna L .: An endangered tree of Indian Thar desert. Indian Forester. 133(11), 1558-1562 .

Chang, J.M., Cheng, C.M., Hung, L. M., Chung, Y. S., Wu, R. Y., 2010 . Potential use of Plectranthus amboinicus in the treatment of rheumatoid arthritis. eCAM. 7(1), 115-120.

Chang, S. L., Chang, Y.C., Yang, C.H., Hong, H.S., 2005. Allergic contact dermatitis to Plectranthus amboinicus masquerading as chronic leg ulcer. Contact Dermatitis. 53, 356-357.

Chet, I., Viterbo, A., Brotman, Y., Lousky, T., 2006. Enhancement of plant disease resistance by biocontrol agent Trichoderma. Life Sciences, Weizmann Institute of Science. URL: http:// www.weizmann.ac.il/

Chiu, Y.J., Huang, T. H., Chiu, C.S., Lu, T. C., Chen, Y. W., Peng, W. H., Chen, C. Y., 2012. Analgesic and antiinflammatory activities of the aqueous extract from Plectranthus amboinicus (Lour.) Spreng. both in vitro and in vivo. Evid. Based Compl. Alt. Med. Article ID 508137. 11 pages.

Chopra, R.N., Nayar, S.L., Chopra, I.C., 1956. The glossary of Indian medicinal plants. CSIR, New Delhi. p.74.

Cliquet, J.B., Stewart, G.R.., 1993. Ammonia assimilation in maize infected with an AM fungus Glomus fasciculatum. Plant Physiol. 101, 865- 871.

Das, K., Dang, R., Shivananda, T. N., Sekeroglu, N., 2007. Influence of biofertilizers on the biomass yield and nutrient content in Stevia rebaudiana Bert. grown in Indian subtropics. J. Med. Plants Res. 1(1), 5-8.

Daughtry, C.S.T., 1990 Direct measurements of canopy structure. Remote Sens. Rev. 5(1), 45-60.

Frank, A.B., 1885. Über die auf Wurzelsymbiose beruhendc Ernahrung gewisser Baume duren unterirdischePilzc. Ber. dtsch. Bot. Ges. 3, 128-145.

Gerdemann, J.W., Nicolson, T.H., 1963. Spores of mycorrhizal endogone species extracted by wet sieving and decanting. Trans. British Mycol. Soc. 46, 235-244.

Giovanneti, M., Mosse, B., 1980. An evolution of technique for measuring vesicular arbuscular mycorrhizal infection in roots. New Phytol. 84, 489-500.

Gomathinayagam, S., Persaud, S. A., Rekha, M., 2012. Comparative study of biological agents, Trichoderma harzianum and Trichoderma viridae for controlling brown spot disease in rice. J. Biopest. 5, 28-32.

Harman, G.E., Howell, C.R., Viterbo, A., Chet, I., Iorito, M., 2004. Trichoderma species- opportunistic, avirulent plant symbionts. Nature Microbiol. Rev. 2, 43-56.

Harsha,V.H., Hebbar, S.S., Shripathi, V., Hegde, G.R., 2003. Ethnomedicobotany of Uttara Kannada District in 
Karnataka, India-Plants in treatment of skin diseases. J. Ethnopharmacol. 84(1), 37-40.

Howell, C.R., 2003. Mechanism employed by Trichoderma species in the biological control of plant disease, the history and evolution of current concepts. Plant Dis. 87, 410 .

Inbar, J., Menendez, A., Chet, I., 1996. Hyphal interactions between Trichoderma harzianum and Sclerotinia sclerotiorum and its role in biological control. Soil Biol. Biochem. 28, 757-763.

Jackson, M.L., 1973. Soil Chemical Analysis. Prentice Hall of India Pvt. Ltd, New Delhi.

Jain, R., Saxena, J., Sharma, V., 2010. The evaluation of free and encapsulated Aspergillus awamori for phosphate solubilization in fermentation and soil-plant system. Appl. Soil Ecol. 46, 90-94.

Johnson, J.F., Paul, L.R., Finley, R.D., 2004. Microbial interaction in the mycorrhizaosphere and their significance for sustainable agriculture. FEMS Microbiol. Ecol. 48, 1-13.

Joner, E.J., Briones, R., Leyval, 2000. Metal binding capacity of arbuscular mycorrhizal fungi. Plant Soil. 226 , 227-234.

Karthikeyan, B., Jaleel, C.A., Changxing, Z., Joe, M.M., Srimannarayan, J., Deiveekasundaram, M., 2008. The effect of AM fungi and phosphorus level on the biomass yield and ajmalicine production in Catharanthus roseus. Eur-Asia J. Biosci. 2, 26-33.

Kirtikar, K.R., Basu, B.D., 1975. Indian Medicinal Plants. $2^{\text {nd }}$ Edn. International Book Distributors, Dehradun. 1971p.

Krik, J. T. O., Allen, R. L., 1965. Dependence of chloroplast pigments synthesis on protein synthetic effects of acitilione. Biochem. Biophys. Res. Comm. 27, 523-530.

Kullnig, C., Mach, R.L., Lorito, M., Kubicek, C.P., 2000. Enzyme diffusion from Trichoderma atroviride (T.harzianum P1) to Rhizoctonia solani is a prerequisite for triggering of Trichoderma ech42 gene expression before mycoparasitic contact. Appl. Environ. Microbiol. 66, 2232-2234.

Kumar, A., Aggarwal, A., Sharma, S., Kaushish, S., 2008. Interactions of arbuscular mycorrhizal fungi and Trichoderma viride on growth of Spilanthes acmella Murr. J. Indian Bot. Soc. 87(1-2), 120-124.

Li, Q., Ling, W., Gao, Y., Li, F., Xiong, W., 2006. Arbuscular mycorrhizal bioremediation and its mechanisms of organic pollutants -contaminated soils.Ying Yong Sheng Tai Xue Bao. 17(11), 2217 -2221.

Lichtenthaler, H.K., 1987. Chlorophylls and carotenoids: Pigments of photosynthetic biomembranes. Methods Enzymol. 148, 350-382.

Lichtenthaler, H.K., Buschmann, C., Döll, M., Fietz, H.-J., Bach, T., Kozel, U., Meier, D., Rahmsdorf, U., 1981. Photosynthetic activity, chloroplast ultrastructure, and leaf characteristics of high-light and low-light plants and of sun and shade leaves. Photosynth. Res. 2, 115- 141.

Lukhoba, C. W., Simmonds, M. S. J., Paton, A. J., 2006. Plectranthus: A review of ethnobotanical uses Journal of Ethnopharmacol. 103, 1-24.
Medina, A., Vassilev, N., Barea, J.M., Azcon, R., 2005. Application of Aspergillus niger - treated agrowaste residue and Glomus mosseae for improving growth and nutrition of Trifolium repens in a $\mathrm{Cd}$ - contaminated soil. J. Biotechnol. 116, 369-378.

Menge, J.A., Timmer, L.W.,1982. Procedures for inoculation of plants with Vesicular-arbuscular mycorrhizae in the laboratory, greenhouse, and field. In: Methods and Principles of Mycorrhizal Research (Ed.: Schenck, N.C.). American Phytopathological Society, St. Paul. pp.59-68.

Michirina, J., Michalikova, A., Konacik, T., Kulichora, R., 1995. Antibiosis, a possible mechanism of antagonistic action of Trichoderma harzianum against Fusarium culmorum. Ocharna Rostlin. 31, 177-184.

Monte, E., Llobell, A., 2003. Trichoderma in Organic Agriculture. Proceedings of World Avocado Congress (Actas V Congreso Mundial del Aguacate). pp.725-733.

Nadkarni, A.K., 1996. Indian materia medica. 2nd Edn. Popular Prakashan, Mumbai. 371p.

Nadkarni, A.K., 2002. Indian Materia Medica. Vol. I. Popular Prakashan, Bombay, India. pp.371-372.

Naseby, D.C., Pascual, J.A., Lynch, J.M., 2000. Effect of biocontrol strains of Trichoderma on plant growth, Pythium ultimum populations, soil microbial communities and soil enzyme activities. J. Appl. Microbiol. 88, 161-169.

Omar, S.A., 1998. The role of rock phosphate solubilizing fungi and vescicular arbuscular mycorrhiza (VAM) in growth of wheat plants fertilized with rock phosphate. World J. Microbiol. Biotechnol. 14, 211-219.

Palani, S., Raja, S., Naresh, R., Kumar, B, S., 2010. Evaluation of nephroprotective, diuretic and antioxidant activities of Plectranthus amboinicus on acetaminophen-induced nephrotoxic rats. Toxicol. Mech. Methods. 20(4), 213221.

Philips, J. M., Hayman, D. S., 1970. Improved procedures for clearing roots and staining parasitic and VAM fungi for rapid assessment of infection. Trans. Brit. Mcol. Soc. 55, 158- 161.

Punamiya, P., Datta, R., Sarkar, D., Barber, S., Patel, M., Das, P., 2010. Symbiotic role of Glomus mosseae in phytoextraction of lead in vetiver grass Chrysopogon zizanioides (L.). J. Hazard. Mater. 177, 465-474.

Rajeshkumar, S., Nisha, M. C., Selvaraj, T., 2008 .Variability in growth, nutrition and phytochemical constituents of Plectranthus amboinicus (Lour) Spreng. as influenced by indigenous arbuscular mycorrhizal fungi. Mj. Int. J. Sci. Technol. 2(02), 431-439.

Reddy, B.N., Raghanender, C.R., Sreevani, A., 2006. Approach for enhancing mycorrhiza mediated disease resistance of tomato damping off. Indian Phytopathol. 59(3), 299-304.

Roldan, A., Diaz, G., Albaladejo, J., 1992. Effect of VAM fungal inoculation on growth and phosphorus uptake of two Hedysarum species in a Xeric Torriorthent soil from Southeast Spain. Arid Soil Res. Rehabil. 6, 33-39.

Rout, O.P., Acharya, R., Mishra, S.K., Sahoo, R., 2012. Pathorchur (Coleus aromaticus): A review of the 
medicinal evidence for its phytochemistry and pharmacology properties. Int. J. Appl. Biol. Pharmaceut. Technol. 3(4), 348-355.

Sandeepa, M. G., 2013. Effect of Glomus mosseae on growth of selected plant species. Int. J. Bio-Pharma Res. 2(6), 144-145.

Sankaranarayanan, C., Sundarababu, R., 2001. Influence of Rhizobium and phosphobacteria on the interaction of VAmycorrhiza, Glomus mosseae and Meloidogyne incognita on black gram. Int. J. Trop. Plant Dis. 19, 133-139.

Sayeeda, K. B., Aditya, K., Tanuja, R., Navroop, K., 2013. Influence of AM fungi (Glomus mosseae, Acaulospora laevis and Gigaspora sp.) alone and in combination with Trichoderma viride on growth responses and physiological parameters of Dianthus caryophyllus Linn. Adv. Biores. 4(2), 13-20.

Schenck, N. C., Perez, Y., 1990. Manual for the Identification of VA Mycorrhizal Fungi. $3^{\text {rd }}$ Edn. INVAM Publications, University of Florida, Gainesville. 245p.

Schreiner, R.P., Mihara, K.L., Mc Daniel, H., Bethlenfavoy, G.J., 1997. Mycorrhizal fungi improves plant and soil functions and interactions. Plant Soil. 188, 199 -207.

Senthilkumar, A., Venkatesalu, V., 2010. Chemical composition and larvicidal activity of the essential oil of Plectranthus amboinicus (Lour.) Spreng against Anopheles stephensi: A malarial vector mosquito. Parasitol. Res. 107(5), 1275-1278.

Shukla, S.K., Yadav, R.L., Suman, A., Singh, P.N., 2008. Improving rhizospheric environment and sugarcane ratoon yield through bioagent amendment farm yard manure in udic ustrochrept soil. Soil Tillage Res. 2480, 1-11.

Sieverding, E., 1991. Vesicular-Arbuscular Mycorrhiza Management in Tropical Agrosystems. Deutsche Gesellschaft für Technische Zusammenarbeit (GTZ). Eschbom. Germany. 371p.

Sivan, A., Chet, I., 1993. Integrated control of Fusarium crown and root of tomato with Trichoderma harzianum in combination with methyl bromide or soil solarization. Crop Prot. 12, 380-386.
Sumana, D.A., Bagyaraj, D.J.. 1999. Selection of efficient VAmycorrhizal fungi for inoculating neem. In: Proceedings of the National Conference of Mychorrhiza (Ed.: Singh, S.). Barkatulla University, Bhopal.

Tanwar, A., Aggarwal, A., Alpa, Kadiyan, N., 2011. Enhanced growth and yield of Capsicum annuum L. with two endomycorrhizal fungi and other bioinoculants. J. Indian Bot. Soc. 90, 351-359.

Tobar, R., Azcon, R., Barea, J.M., 1994a. Improved nitrogen uptake and transport from $15 \mathrm{~N}$-lebelled nitrate by external hyphae of arbuscular mycorrhizae under water stressed conditions. New Phytol. 126, 119-122.

Tobar, R., Azcon, R., Barea, J.M., 1994b. The improvement of plant $\mathrm{N}$ acquisition from an ammonium-treated, drought stressed soil by the fungal symbiont in arbuscular mycorrhizae. Mycorrhiza. 4, 105-108.

Tondje, P.R., Roberts, D.P., Bon, M.C., Widner, T., Samuels, G.L., Ismaiel, A., Begoude, A.D., Tchana, T., NyembTshomb, E., Ndounbe-Nkeng, M., Bateman, R., Fontem, D., Hebbar, K.P., 2007. Isolation and identification of mycoparasitic isolates of Trichoderma asperellum with potential for suppression of black pod disease of cacao in cameroon. Biol. Control. 43, 202-212.

Trappe, J. M., 1982. Synoptic key to the genera and species of zygomycetous mycorrhizal fungi. Phytopathol. 72, 1102 1108.

Vassilev, N., Medina, A., Azcon, R., Vassileva, M., 2006. Microbial solubilization of rock phosphate on media containing agro-industrial wastes and effect of the resulting product on plant growth and P-uptake. Plant Soil. 287, 77-84.

Vera, R., Mondon, J.M., Pieribattesti, J.C., 1993 .Chemical composition of the essential oil and aqueous extract of Plectranthus amboinicus. Planta Med. 59, 182-183.

Woo, S.L., Scala, F., Ruocco, M., Lorito, M., 2006. The molecular biology of the interactions between Trichoderma spp., phytopathogenic fungi and plants. Phytopathol. 96, 181-185.

\section{How to cite this article:}

Kasliwal, S., Nezhad, H. R., Srinivasamurthy, K. M., 2016. Studies on effects of inoculation of Glomus mosseae and plant growth promoting rhizomicroorganisms (PGPR) on Plectranthus amboinicus (Lour.) Spreng. Int. J. Curr. Res. Biosci. Plant Biol. 3(7), 127-137. doi: http://dx.doi.org/10.20546/ijcrbp.2016.307.018 